\title{
Neurokinin 1 Receptor Internalization in Spinal Cord Slices Induced by Dorsal Root Stimulation Is Mediated by NMDA Receptors
}

\author{
Juan Carlos G. Marvizón, ${ }^{1}$ Vicente Martínez, ${ }^{1}$ Eileen F. Grady, ${ }^{3}$ Nigel W. Bunnett,, ${ }^{3,4}$ and Emeran A. Mayer ${ }^{1,2}$ \\ ${ }^{1}$ CURE: Digestive Diseases Research Center, Neuroenteric Disease Program, Department of Medicine, and ${ }^{2}$ Department \\ of Physiology, University of California, Los Angeles, California 90073, and ${ }^{3}$ Departments of Surgery and ${ }^{4}$ Physiology, \\ University of California, San Francisco, California 94143
}

The excitability of spinal neurons that transmit pain is modulated by glutamate and substance $P(S P)$. Glutamate is an excitatory neurotransmitter in the dorsal horn, and its effects are enhanced by SP acting on neurokinin 1 receptors (NK1Rs). We assessed activation of NK1Rs by studying their internalization in spinal cord slices. NK1Rs were localized in sections from the slices by using immunohistochemistry combined with fluorescence and confocal microscopy. Incubating the slices with SP induced internalization in most NK1R-positive neurons in laminae $\mathrm{I}, \mathrm{I}_{\mathrm{O}}$, and $\mathrm{X}$ and in half of NK1R-positive neurons in laminae III-V. SP-induced internalization was abolished by the specific NK1R antagonist L-703,606 (1 $\mu \mathrm{M})$. Stimulating the dorsal root with long-duration $(0.4 \mathrm{msec})$ pulses evoked EPSPs in dorsal horn neurons with latencies consistent with the conduction speed of $\mathrm{A} \partial$ - and C-fibers. High-frequency $(100 \mathrm{~Hz})$ stimulation of the dorsal root with these pulses induced NK1R internalization in neurons in laminae $\mathrm{I}-\mathrm{II}_{\mathrm{o}}$ of the stimulated side of the slice but not in the contralateral side or in other laminae. Stimulation at lower frequencies (1 and $10 \mathrm{~Hz}$ ) failed to elicit significant internalization, suggesting that the release of SP is frequency-dependent. Internalization produced by the $100 \mathrm{~Hz}$ tetanus was mimicked by NMDA and blocked by an NMDA antagonist, 2-amino-5-phosphonopentanoic acid, but not by the AMPA and kainate antagonist CNQX. The NK1R antagonist L-703,606 abolished the internalization produced by $100 \mathrm{~Hz}$ stimulation or NMDA. Therefore, the release of SP in the dorsal horn appears to be controlled by NMDA receptors.

Key words: C-fibers; central sensitization; dorsal horn; glutamate receptor; internalization; LTP; NK1 receptor; NMDA receptor; slices; substance $P$
Many instances of hyperalgesia seem to be caused by an increase in the excitability of spinal sensory neurons, termed central sensitization, induced by an increased activity of nociceptive afferents (McMahon et al., 1993; Yaksh, 1993; Zieglgänsberger and Tolle, 1993). Phenomena related to central sensitization include "wind-up," a progressive increase in the number of action potentials evoked per stimulus when afferent fibers are repeatedly stimulated (Mendell, 1966; Dickenson and Sullivan, 1987), and long-term potentiation (LTP) of dorsal horn synapses (Randic et al., 1993; Liu and Sandkühler, 1995). LTP of excitatory synapses in nociceptive pathways may cause hyperalgesia, and its long duration could explain the persistence of certain types of chronic pain.

Substantial evidence suggests that neurokinin and glutamate receptors play an important role in mediating central sensitization (Xu et al., 1992). SP causes a prolonged depolarization of dorsal horn neurons (Murase and Randic, 1984), enhances their responses to $\mathrm{C}$-fiber input, and participates in wind-up (Kellstein et al., 1990), whereas NMDA receptors are required for the

\footnotetext{
Received April 2, 1997; revised Aug. 8, 1997; accepted Aug. 12, 1997.

This work was supported by National Science Foundation Grant IBN-9510314 to E.F.G., National Institutes of Health Grants DK40919 and DK48351 to E.A.M, DK43207 and DK39957 to N.W.B, and DK41301 to CURE: Digestive Diseases Research Center. A pilot and feasibility grant to J.C.M. and access to facilities in the Morphology/Imaging Core and Animal Models Core were provided by CURE Digestive Diseases Research Center. We thank Dr. Mirjana Randic, Dr. Rok Cerne, Dr. Lawrence Kruger, Dr. Thomas O’Dell, Dr. Catia Sternini, and Dr. Nicholas Brecha for their advice and Dr. Steve Vigna for the NK1R antibody.

Correspondence should be addressed to Juan Carlos G. Marvizón, University of California Los Angeles Neuroenteric Disease Program, West Los Angeles Veterans Administration Medical Center, Building 115, 11301 Wilshire Boulevard, Los Angeles, CA 90073.

Copyright (C) 1997 Society for Neuroscience $\quad 0270-6474 / 97 / 178129-08 \$ 05.00 / 0$
}

induction of both wind-up (Davies and Lodge, 1987; Dickenson and Sullivan, 1987) and LTP (Randic et al., 1993; Liu and Sandkühler, 1995) in the dorsal horn. Numerous observations indicate that glutamate and neurokinins act synergistically in the dorsal horn. Spinal application of SP and glutamate increases the responses of dorsal horn neurons to mechanical stimulation of the skin (Dougherty et al., 1995). Glutamate and SP coexist in primary afferent terminals (Battaglia and Rustioni, 1988; De Biasi and Rustoni, 1988), whereas neurokinin 1 receptors (NK1Rs) and glutamate receptors are coexpressed in dorsal horn neurons, which have responses to glutamate that are enhanced by SP (Womack et al., 1988; Randic et al., 1990; Rusin et al., 1993a,b). Conversely, presynaptic NMDA receptors found in afferent terminals in the dorsal horn may control the release of SP and other neuropeptides (Liu et al., 1994b, 1997).

After agonist binding, NK1Rs are internalized (Mantyh et al., 1995; Grady et al., 1996), a process that appears to mediate receptor resensitization (Garland et al., 1996). Recent studies (Mantyh et al., 1995) have used the internalization of NK1Rs in dorsal horn neurons to demonstrate their activation by noxious stimulation in vivo. Spinal cord slices with attached dorsal roots allow controlled application of drugs and electrical stimulation and preserve many of the synapses present in the intact tissue. These characteristics make this preparation suitable to study the internalization of NK1Rs in dorsal horn neurons as a marker of their activation by various stimuli. Here, we have used spinal cord slices (1) to observe NK1R internalization induced in vitro; (2) to determine whether endogenous neurokinins are released in the slices by electrical stimulation of the dorsal root; and (3) to 
investigate whether NMDA receptors are involved in neurokinin release.

\section{MATERIALS AND METHODS}

Reagents. CNQX, 2-amino-5-phosphonopentanoic acid (AP-5), L703,606, and NMDA were from Research Biochemicals International (Natick, MA). Metofane (methoxyflurane) was from Pitman-Moore (Mundelein, IL). PBS (in mM: $138 \mathrm{NaCl}, 2.7 \mathrm{KCl}$, and $10 \mathrm{Na}^{+}$phosphate, $\mathrm{pH}$ 7.4) and thiorphan were obtained from Sigma Chemical Co. (St. Louis, MO). SP was from Molecular Research Laboratories (Durham, NC). Slow Fade was from Molecular Probes (Eugene, OR). All other reagents were purchased from standard commercial sources.

Slice preparation. Transverse slices of $400 \mu \mathrm{m}$, some with one dorsal root attached, were cut from a lumbar segment (L2-L5) of the spinal cord of a young rat (14-28 d) using a Vibratome (Technical Products International, Inc., St. Louis, MO), as described previously (Randic et al., 1993). Slices were kept in artificial CSF (ACSF; in mM: $124 \mathrm{NaCl}, 1.9$ $\mathrm{KCl}, 26 \mathrm{NaHCO}_{3}, 1.2 \mathrm{KH}_{2} \mathrm{PO}_{4}, 1.3 \mathrm{MgSO}_{4}, 2.4 \mathrm{CaCl}_{2}$, and 10 glucose, bubbled with $95 \% \mathrm{O}_{2}$ and $5 \% \mathrm{CO}_{2}, \mathrm{pH} 7.4,305 \mathrm{mOsm}$ ) except during their preparation, when $\mathrm{NaCl}$ was iso-osmotically replaced by sucrose (215 $\mathrm{mM})$, and the concentration of $\mathrm{KCl}$ was increased to $5 \mathrm{mM}$. Immediately after cutting, slices were incubated at $35^{\circ} \mathrm{C}$ for $1-1.5 \mathrm{hr}$ in ACSF containing $5 \mathrm{~mm} \mathrm{KCl}$.

Electrophysiology. Intracellular recordings from neurons in laminae I-II were performed using sharp electrodes as described previously (Randic et al., 1993). Recording electrodes (100-200 M $\Omega$ ) were pulled from aluminosilicate glass tubing $(1.0 \mathrm{~mm}$ outer diameter, $0.53 \mathrm{~mm}$ inner diameter) and filled with $3 \mathrm{~m}$ potassium acetate and $10 \mathrm{~mm} \mathrm{KCl,} \mathrm{pH}$ 7.2. Slices were kept submerged in a recording chamber perfused at 3-6 $\mathrm{ml} / \mathrm{min}$ with $\mathrm{ACSF}$ at $35^{\circ} \mathrm{C}$. Neurons were impaled by slowly advancing the recording electrode and oscillating the capacity compensation circuit of an Axoprobe 1A amplifier (Axon Instruments, Foster City, CA). Recordings were performed from neurons that had a resting membrane potential negative to $-50 \mathrm{mV}$, action potentials that overshot $0 \mathrm{mV}$, and membrane resistance $>60 \mathrm{M} \Omega$.

EPSPs were evoked by stimulating the whole root distally $(3-7 \mathrm{~mm})$ from the slice with a hook platinum bipolar electrode connected to a Grass S-88 stimulator through a stimulus-isolating unit operating in capacity mode. The duration of the electrical pulses was $0.4 \mathrm{msec}$, and their intensity was adjusted in the range of 5-30 V to yield EPSPs of 5-20 $\mathrm{mV}$ without evoking action potentials. Sweeps $(200 \mathrm{msec})$, including the response to a current step $(-0.1$ to $-0.3 \mathrm{nA}, 30-50 \mathrm{msec})$ and the evoked EPSP, were analyzed on-line (Neuropro; RC Electronics, Santa Barbara, CA) to measure baseline membrane potential and resistance, and the latency, amplitude, and slope of the evoked EPSP. Conduction speeds were calculated by dividing the length of the root stimulated by the latency of the evoked EPSPs. LTP or long-term depression (LTD) were induced with a $100 \mathrm{~Hz}$ tetanus (three trains of $1 \mathrm{sec}$ every $10 \mathrm{sec}$, pulses identical to those used to sample EPSPs) after sampling EPSPs at $0.03 \mathrm{~Hz}$ for at least $10 \mathrm{~min}$ to establish a baseline, and assessed by recording evoked EPSPs for an additional 20-80 min.

Slice treatments. The procedure for electrical stimulation of the dorsal root was similar to that used to evoke EPSPs. One dorsal root was used to stimulate the corresponding dorsal horn, whereas the contralateral dorsal horn served as control. Lack of good contact between the root and the slice usually derives from not cutting the slice precisely at the point of entrance of the root, or from damage to the root at its point of contact with the slice. Slices were inspected for damage to the root using a dissection microscope, and those judged unsatisfactory were discarded. Slices were placed in the recording chamber perfused at 3-6 $\mathrm{ml} / \mathrm{min}$ with $\mathrm{ACSF}$ at $35^{\circ} \mathrm{C}$, and the whole dorsal root was stimulated with square pulses of $20 \mathrm{~V}$ and $0.4 \mathrm{msec}$ duration. Stimulation consisted of 300 pulses in three trains at $100 \mathrm{~Hz}(1 \mathrm{sec})$ or $10 \mathrm{~Hz}(10 \mathrm{sec})$ separated by $10 \mathrm{sec}$ or 1 train at $1 \mathrm{~Hz}(5 \mathrm{~min})$. After stimulation, slices were kept in the chamber for 10-15 min and then fixed. The stimulated side of the slice was marked with a V-shaped cut in the ventral horn. To avoid bias, this mark was only used to identify the stimulated side of the sections after the cells were counted.

Drug treatment was done by either incubating the slices at $35^{\circ} \mathrm{C}$ in $2-5$ $\mathrm{ml}$ of ACSF bubbled with $95 \% \mathrm{O}_{2}$ and $5 \% \mathrm{CO}_{2}$ containing the appropriate concentration of drug or, in experiments in which the root was stimulated, by adding the drug to ACSF perfused through the recording chamber.

Capsaicin injection. In vivo noxious stimulation was performed as described (Mantyh et al., 1995). Male Sprague Dawley rats (2 months old) were anesthetized with enflurane and injected subcutaneously in the hindpaw with $20 \mu \mathrm{l}$ of capsaicin dissolved $(5 \mathrm{mg} / \mathrm{ml})$ in $5 \%$ polyoxyethylenesorbitan mono-oleate (Tween 80 ). After $7 \mathrm{~min}$ the rats were deeply anesthetized with sodium pentobarbital $(60 \mathrm{mg} / \mathrm{kg}$ of body weight) and perfused through the ascending aorta with $100 \mathrm{ml}$ of $0.1 \mathrm{M}$ PBS, pH 7.4, followed by $500 \mathrm{ml}$ of PBS containing $4 \%$ paraformaldehyde and saturated picric acid $\left(4^{\circ} \mathrm{C}\right)$. The lumbar spinal cord was then removed and processed like the slices.

Immunohistochemistry. The procedure used was similar to that described by Mantyh et al. (1995). Slices were fixed in PBS containing 4\% paraformaldehyde and saturated picric acid for $3-16 \mathrm{hr}$ at $4^{\circ} \mathrm{C}$ and cryoprotected by incubating with $20 \%$ sucrose in phosphate buffer $(0.1 \mathrm{M}$, $\mathrm{pH} 7.4$ ) for $12-24 \mathrm{hr}$ at $4^{\circ} \mathrm{C}$. Each slice was then frozen on dry ice and cut into transverse sections ( $50 \mu \mathrm{m}$, six to eight sections per slice). Sections were washed once with PBS and twice with PBS containing $1 \%$ normal goat serum and $0.3 \%$ Triton X-100. Then, sections were incubated at room temperature for $1 \mathrm{hr}$, and at $4^{\circ} \mathrm{C}$ for $36-40 \mathrm{hr}$, with the anti-NK1R primary antibody diluted 1:3000 in PBS containing 10\% normal goat serum and $0.3 \%$ Triton X-100. The primary antibody was a polyclonal rabbit antibody (11826-5, a generous gift from Dr. Steve Vigna, Duke University Medical Center, Durham, NC) raised against a 15 amino acid peptide sequence at the C-terminal of the rat NK1R (Vigna et al., 1994; Mantyh et al., 1995). After three washes with PBS, sections were incubated for $2 \mathrm{hr}$ at room temperature with the secondary antibody (goat anti-rabbit IgG FITC, affinity-purified; Cappel, Durham, NC) diluted 1:100 in PBS, $10 \%$ normal goat serum, and $0.3 \%$ Triton X-100. Sections were washed three more times with PBS and mounted in Slow Fade.

Confocal microscopy. Neurons were studied as described (Grady et al., 1996) using an MRC 1000 confocal microscope, (Bio-Rad, Hercules, CA) equipped with a krypton-argon laser $(488,565$, and $647 \mathrm{~nm}$ lines) and $\mathrm{T} 1$ and T2A filter blocks, attached to a Zeiss Axiovert microscope. Sections were observed with a Plan Apochromat $100 \times$ oil immersion objective with a numerical aperture of $1.4(\infty 0.7)$. Images were collected using an aperture of $2-5 \mathrm{~mm}$ and zoom of $1-3$. Optical sections were taken at 0.5 $\mu \mathrm{m}$ intervals through the tissue. The combination of objective and microscope settings used resulted in a resolution in the $x$ - and $y$-axis of $170-200 \mathrm{~nm}$ and in the $z$-axis of $230-400 \mathrm{~nm}$. Images of $768 \times 420$ pixels were obtained and processed using Adobe Photoshop 3.0, (Adobe Systems Inc., Mountain View, CA) and printed using a Fujix Pictography 3000 printer.

Neuron counting. A Leitz Orthoplan (E. Leitz, Inc., Rockleigh, NJ) fluorescence microscope fitted with a $50 \times$ oil immersion objective (Leitz NPL Fluotar) was used to count NK1R immunoreactive neuronal somas. Counting was done according to the following procedure: (1) the observation field was moved systematically along each of the Rexed laminae while focusing up and down through the section to view the neurons; (2) neurons were considered to have internalized receptors when $\geq 10$ endosomes were observed inside the soma and proximal dendrites contiguous with it; (3) neurons were grouped in the following regions: laminae

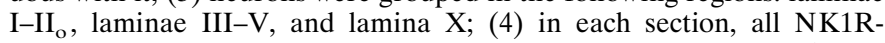
positive neuronal somas in these regions were counted and classified as having or not having internalized NK1Rs, except that in some experiments only neurons in laminae $\mathrm{I}-\mathrm{II}_{\mathrm{o}}$ were counted; (5) at least five (and frequently all) of the six to eight sections obtained per slice were examined; (6) neurons in the right and left side of the sections were counted separately; (7) in stimulated slices, the right and left side of each section was labeled as stimulated or contralateral by locating a notch carved in the ventral horn (see Slice treatments); (8) another investigator independently reexamined the sections to verify the counting; (9) data of the sections were added, and results were expressed as percentage of NK1R-positive neurons showing internalization in each region per slice or hemislice (stimulated or contralateral side); and (10) results of three or four slices were averaged to calculate the mean \pm SEM.

Prism software (GraphPad Software, San Diego, CA) was used for data processing and statistical analysis. The statistical significance of differences between pairs of values was determined by performing a one-way ANOVA for each lamina followed by Bonferroni's multiple comparison test.

\section{RESULTS}

\section{NK1R immunoreactive neurons in spinal cord slices}

The NK1R was localized by immunofluorescence in fixed sections prepared from live transverse spinal cord slices. The NK1R covered most of the somatic and dendritic surface of the neurons. 

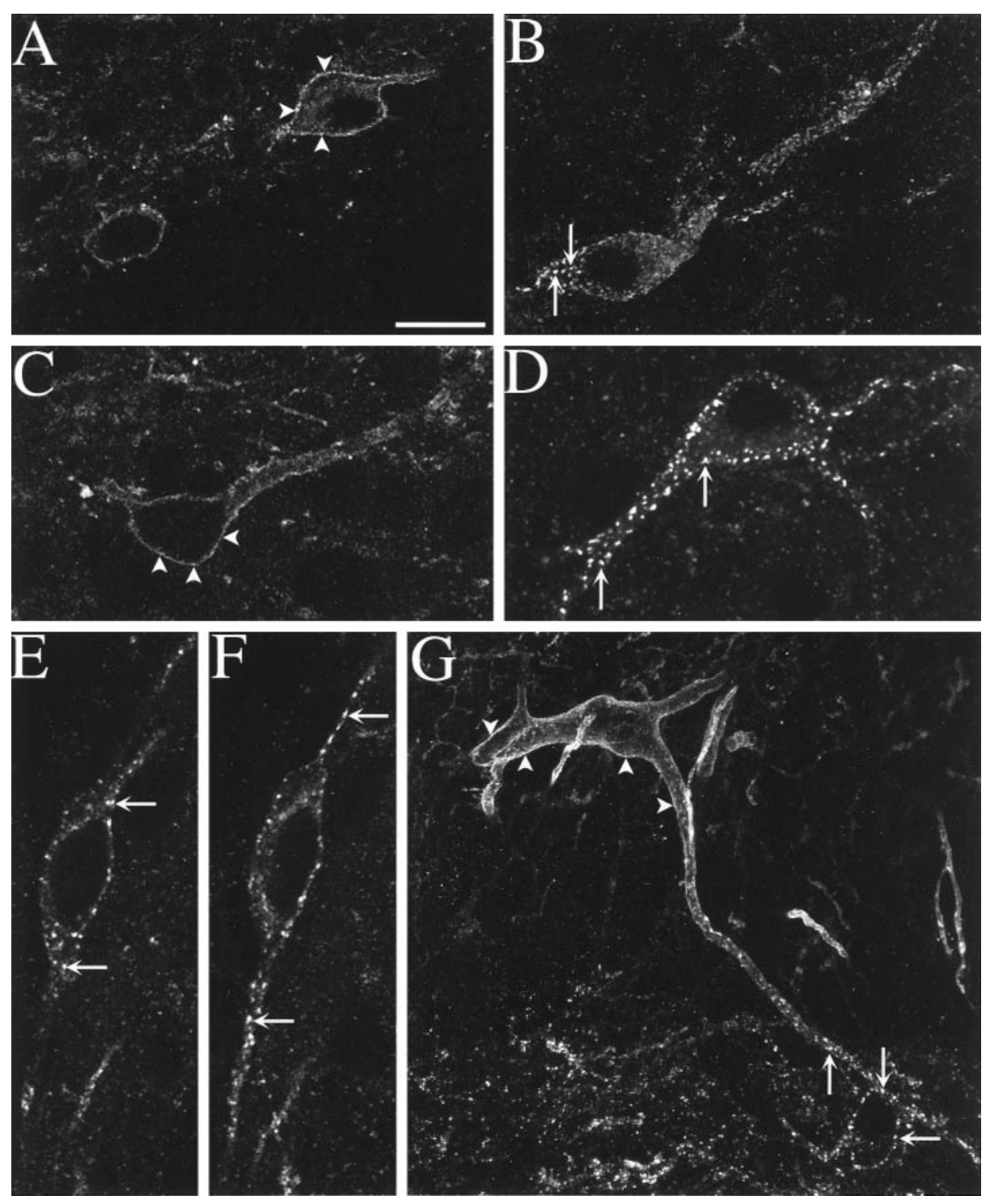

Figure 1. Fluorescent confocal images of NK1R-immunoreactive neurons in the dorsal horn. Arrowheads indicate surface labeling, and arrows indicate NK1Rs internalized in endosomes. $A-F$, Spinal cord slices were incubated for $10 \mathrm{~min}$ at $35^{\circ} \mathrm{C}$ with $\mathrm{ACSF}$ alone $(A, C)$ or containing $100 \mathrm{~nm} \mathrm{SP}(B, D, E, F) . A$, Lamina I neurons in a control slice (1 optical section). $B$, Lamina I neuron showing NK1R internalization after incubation with SP (8 optical sections). $C$, Lamina III neuron in a control slice (1 optical section). $D$, Lamina III neuron in a slice incubated with SP (5 optical sections). $E$, $F$, Lamina I neuron in a slice incubated with SP; single central $(E)$ and superficial $(F)$ optical sections show internalization in the soma and the dendrites, respectively. $G$, Lamina III neuron with a dendrite projecting dorsally to lamina I (at the bottom) in a section cut from the lumbar (L4) spinal cord of a rat injected with capsaicin $(100 \mu \mathrm{g})$ in the hindpaw. This panel is a computer-generated juxtaposition of two confocal images, one in lamina III (28 optical sections) and other in laminae I and II (34 optical sections). Scale bar: $A, G, 20 \mu \mathrm{m} ; B$, $13.3 \mu \mathrm{m} ; C-F, 11.6 \mu \mathrm{m}$.
Sections prepared directly from a fixed rat, labeled using the same immunohistochemistry procedure, yielded high-quality images (Fig. 1G) similar to those in earlier reports (Mantyh et al., 1995). Sections prepared from the slices also gave images of good quality (Fig. $1 A-F$ ), although sometimes they had a slightly higher background. We expected to find some variability in the number of NK1R-immunoreactive neurons between the different histological sections obtained from a slice, because neurons in the surface of the slice tend to be damaged when cutting with the Vibratome, whereas cells inside the slice are better protected. Sections superficial to the slice (first and last cut) could be identified because they have rugged, broken edges. These superficial sections did have less neurons and uneven thickness, and they were often discarded after sectioning or excluded from the cell counting. We found little variability in the number of NK1R-positive neurons between the rest of the sections from a slice.

Earlier reports (Bleazard et al., 1994; Liu et al., 1994a; Brown et al., 1995; Mantyh et al., 1995), indicated that NK1R-positive neurons are found in all of the Rexed laminae of the dorsal horn except lamina II. Our observations confirmed these reports. However, although NK1R-positive neurons were practically absent in the internal portion of lamina II (lamina $\mathrm{II}_{\mathrm{i}}$ ), some NK1R- positive neurons appear to be present in the outermost portion of lamina II (lamina $\mathrm{II}_{\mathrm{o}}$ ). The number of NK1R-immunoreactive neurons per slice was as follows: laminae $\mathrm{I}_{\text {and }} \mathrm{II}_{\mathrm{o}}, 195 \pm 15(n=$ 15); laminae III and IV, $238 \pm 30(n=9)$; laminae $\mathrm{V}, 93 \pm 13$ $(n=9)$; and lamina X, $28 \pm 7(n=15)$. Some large NK1Rpositive neurons were found in the lateral spinal nucleus $(27 \pm 3$ neurons per slice; $n=15$ ), i.e., the dorsalmost part of the dorsolateral white matter. Several neurons in laminae III and IV had a large, dorsally directed dendritic arbor that traversed lamina II and spread in lamina I (see Figs. $1 G, 5 D$ ).

In untreated slices (control in Figs. 2, 4; $n=4$ slices), NK1R immunoreactivity was localized to the cell surface in practically all NK1R-positive neurons in laminae III-V (99 $\pm 0.2 \%, 224-530$ NK1R-positive neurons per slice) or lamina X (98 $\pm 2 \%, 9-48$ NK1R-positive neurons per slice) and most NK1R-positive neurons in laminae $\mathrm{I}_{-} \mathrm{II}_{\mathrm{o}}(82 \pm 2 \%, 148-294 \mathrm{NK} 1 \mathrm{R}$-positive neurons per slice). It is unlikely that the baseline internalization in laminae $\mathrm{I}-\mathrm{II}_{\mathrm{o}}$ was caused by a continuous release of neurokinins, because it was not abolished by incubating the slices for $40 \mathrm{~min}$ with the NK1R antagonist L-703,606 (1 $\mu \mathrm{M}$; Fig. 2). It may be attributable to neurokinin release during preparation of the slices and the inability of a few neurons to recycle the receptor to the 


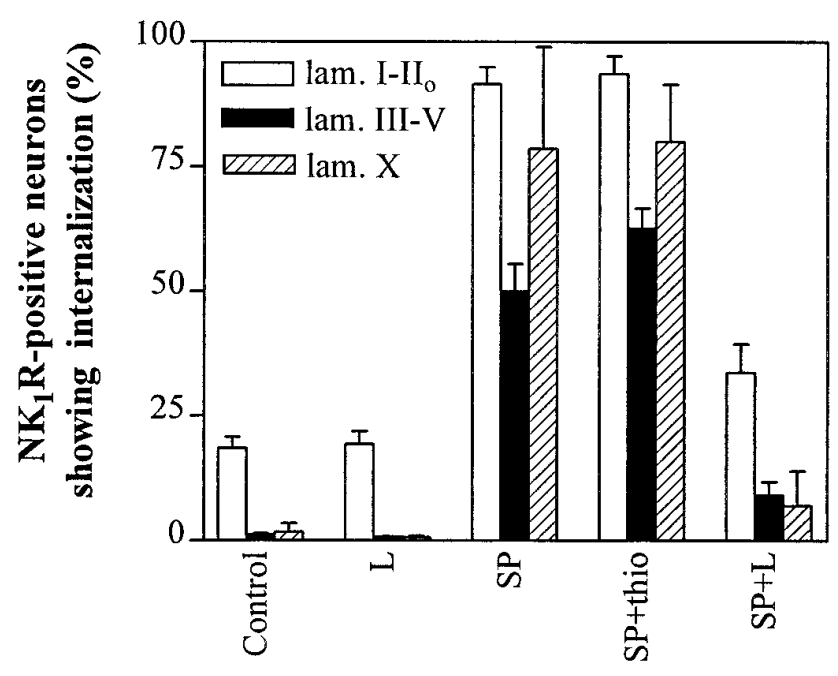

Treatment

Figure 2. Percentage of NK1R-positive neurons showing internalization after incubation with SP and a NK1R antagonist. Slices were incubated at $35^{\circ} \mathrm{C}$ in ACSF bubbled with $95 \% \mathrm{O}_{2}$ and $5 \% \mathrm{CO}_{2}$ as follows: Control, no additions; $L, 1 \mu \mathrm{M} \mathrm{L-703,606} \mathrm{for} 40 \mathrm{~min}$; $S P$, $100 \mathrm{~nm}$ SP for $10 \mathrm{~min}$; $S P+$ thio, $10 \mu \mathrm{M}$ thiorphan for $20 \mathrm{~min}$ adding $100 \mathrm{nM}$ SP during the last 10 $\min ; S P+L$, and $1 \mu \mathrm{M} \mathrm{L}-703,606$ for 40 min adding $100 \mathrm{~nm}$ SP during the last $10 \mathrm{~min}$. Bars represent the percentage of NK1-positive neurons with internalization in laminae $\mathrm{I}_{-} \mathrm{II}_{\mathrm{o}}, \mathrm{III}-\mathrm{V}$, or X. Values are mean $\pm \mathrm{SEM}$ of three slices, except the control (4 slices). Significant differences (ANOVA, $p<0.001$ ) were found between control and SP, control and SP+thio, SP and $\mathrm{L}$, and $\mathrm{SP}$ and $\mathrm{SP}+\mathrm{L}$ in all three regions. Less pronounced inhibition of internalization was obtained with $100 \mathrm{~nm} \mathrm{L-703,606} \mathrm{(data} \mathrm{not} \mathrm{shown).}$

membrane during the recovery period. Confocal microscopy confirmed the absence of internalization in untreated slices; surface immunofluorescence was detected in single optical sections taken through the center of neurons in laminae I and III (Fig. 1A,C).

\section{NK1R internalization produced by SP application}

Incubating spinal cord slices with SP (100 nM) induced NK1R internalization into multiple discrete vesicles, as determined by confocal microscopy (Fig. $1 B, D-F$ ). SP was applied for $10 \mathrm{~min}$, the time required for the internalization process to reach its peak (Mantyh et al., 1995). Single confocal optical sections confirmed that the internalization occurred both in the soma (Fig. $1 E$ ) and the dendrites (Fig. $1 F$ ). Internalization occurred in all regions of the dorsal horn $(p<0.001$ compared with control slices $)$ and was blocked ( $p<0.001$ compared with SP alone; Fig. 2) by the specific, nonpeptide NK1R antagonist L-703,606 (1 $\mu \mathrm{M}$, Cascieri et al., 1992). Hence, NK1Rs and the mechanisms mediating their internalization were functional in the slices.

SP-induced NK1R internalization (Fig. 2, $n=3$ slices) was observed in nearly all NK1R-positive neurons in laminae $\mathrm{I}_{-} \mathrm{II}_{\mathrm{o}}$ (92 \pm 3\%, 123-196 NK1R-positive neurons per slice), lamina X (79 $\pm 21 \%, 4-24$ NK1R-positive neurons per slice), and the lateral spinal nucleus $(98 \pm 2 \%, 21-27$ NK1R-positive neurons per slice), but only in $50 \pm 5 \%$ of NK1R-positive neurons in laminae III-V (187-204 NK1R-positive neurons per slice). To ensure that SP penetrates the slices, we used it at relatively high concentrations, $100 \mathrm{nM}, 30$ and 600 times the $K_{\mathrm{D}}$ of SP for lowand high-affinity binding sites in the spinal cord, respectively (Routh and Helke, 1995). We wondered whether this difference was because of a greater degradation of SP in laminae III-V by endogenous neutral endopeptidase (NEP, EC 3.4.24.11). Com- bining SP with the NEP inhibitor thiorphan $(10 \mu \mathrm{M})$ resulted in a small increase (to $63 \pm 4 \%$; $p<0.05$ compared with SP alone) in the number of neurons with internalized NK1Rs in this area (Fig. 2 ), which is consistent with reports showing that peptidase inhibitors increase extracellular SP in the deep dorsal horn (Duggan et al., 1992). Thiorphan alone did not increase NK1R internalization in any of the regions studied ( $p>0.05$, data not shown). In any case, $35 \%$ of the neurons in laminae III-V failed to show internalization in the presence of SP combined with thiorphan, suggesting that some neurons in laminae III-V may be unable to internalize the NK1R in their somas. Neurons in laminae III-V consistently internalized NK1R less readily than lamina I neurons in all treatments used in this study, including noxious stimulation in vivo (Fig. 1G) (Mantyh et al., 1995).

\section{NK1R internalization induced by electrical stimulation of the dorsal root}

To verify that root stimulation elicited action potentials that reached the dorsal horn, we performed intracellular recordings from neurons in laminae I and II. Electrical pulses (5-30 V, 0.4 msec) delivered to the root evoked EPSPs in 14 of 14 neurons recorded. In agreement with earlier reports (Li and Bak, 1976; Yoshimura and Jessell, 1990; Randic et al., 1993; Liu and Sandkühler, 1995), pulses of relatively long duration $(0.4 \mathrm{msec})$ evoked EPSPs with long latencies consistent with the conduction speed of $\mathrm{C}$ - and A $\mathrm{A}$-fibers. EPSPs in the experiment shown in Figure 3 appeared to be monosynaptic, because they had a constant latency of $12 \mathrm{msec}$. From this latency value and the length of dorsal root stimulated $(5 \mathrm{~mm})$, we calculated a conduction speed of 0.4 $\mathrm{m} / \mathrm{sec}$, which is consistent with the conduction speed of C-fibers (Li and Bak, 1976; Swett and Bourassa, 1981). High-frequency stimulation of the dorsal root (three trains of $1 \mathrm{sec}$ at $100 \mathrm{~Hz}$, separated $10 \mathrm{sec}$ ) potentiated synaptic responses in three of four dorsal horn neurons (Fig. 3). In these three neurons, EPSP amplitudes were increased to $155 \pm 10 \%(n=3)$ of baseline for up to $80 \mathrm{~min}$, suggesting that LTP was induced. In the remaining neuron, EPSP amplitude was substantially decreased for $80 \mathrm{~min}$ after the tetanus (data not shown), suggesting the induction of LTD. The presence of LTP and LTD in these synapses has been demonstrated by other investigators (Randic et al., 1993; Liu and Sandkühler, 1995).

We then investigated whether electrical stimulation of the dorsal root entering the slice was able to induce NK1R internalization through the release of endogenous SP. Pulses of $20 \mathrm{~V}$ and $0.4 \mathrm{msec}$ were delivered using a bipolar electrode stimulating the whole root. After high-frequency stimulation $(100 \mathrm{~Hz}$, three trains of $1 \mathrm{sec}$ ) of the dorsal root (Fig. $4 ; n=4$ slices), the percentage of NK1R-positive neurons with internalized receptors was increased in laminae $\mathrm{I}_{-} \mathrm{II}_{\mathrm{o}}$ of the stimulated side (to $53 \pm$ $3 \%$; $p<0.001 ; 84-124$ NK1R-positive neurons per hemislice), but not of the contralateral side $(18 \pm 2 \%$; 59-136 NK1Rpositive neurons per hemislice). Figure $5 A, B$ shows confocal images of representative neurons in the contralateral and stimulated side of the slice, respectively. The increase in internalization produced by high-frequency stimulation was abolished by the NK1R antagonist L-703,606 (5 $\mu$, Fig. 4), perfused for $10 \mathrm{~min}$ before and after the tetanus. Hence, this stimulation protocol appears to induce the release of endogenous SP or other neurokinins from primary afferent terminals or secondary dorsal horn neurons. Crisp surface immunoreactivity was found in neuronal somas in deeper laminae of the stimulated side of the slices (Fig. $5 C, D)$; neurons with internalization were $2 \pm 1 \%$ in laminae 

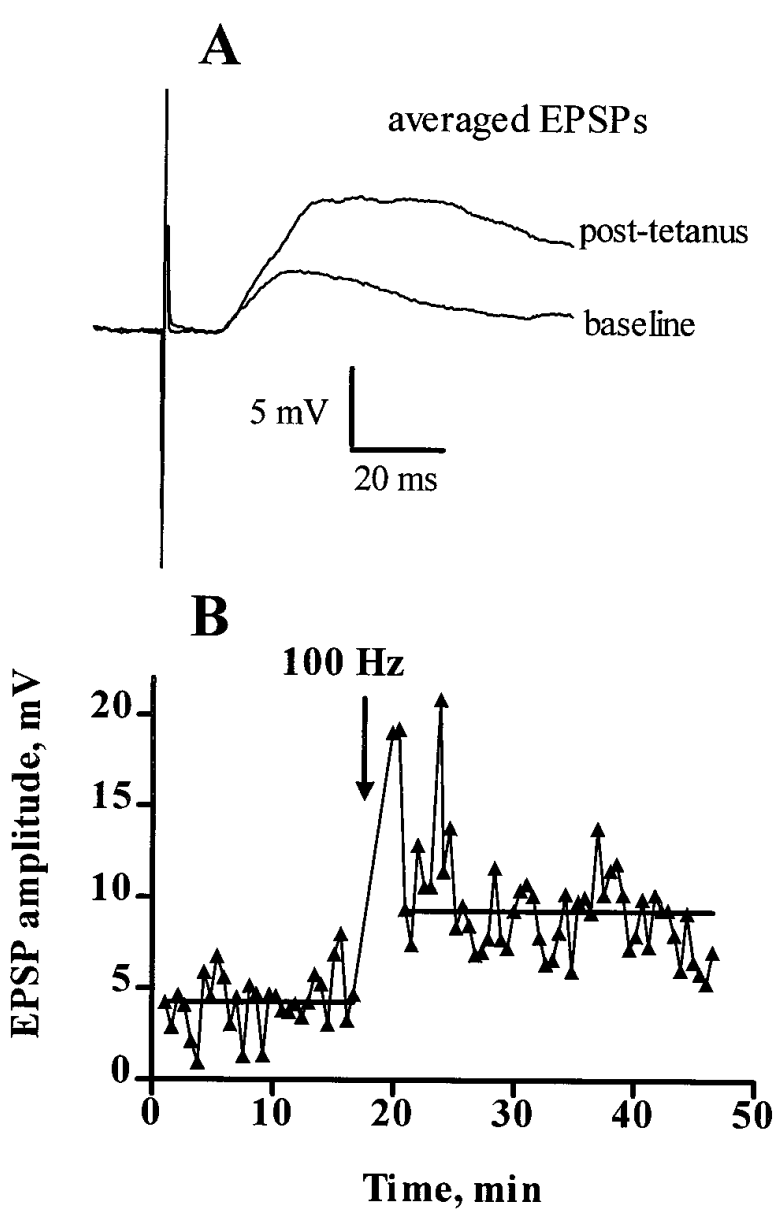

Figure 3. EPSPs and LTP of dorsal horn synapses. Intracellular recording from a dorsal horn neuron (laminae I-II) in a spinal cord slice. The resting membrane potential of the neuron was $-63 \mathrm{mV}$, its input resistance was $160 \mathrm{M} \Omega$, and its time constant was $5 \mathrm{msec}$. The cell was held at $-71 \mathrm{mV}$ by passing current $(-20$ to $-60 \mathrm{pA})$ through the recording electrode. EPSPs were evoked every $30 \mathrm{sec}$ by stimulating the dorsal root, $5 \mathrm{~mm}$ away from the slice, with pulses of $8.8 \mathrm{~V}$ and $0.4 \mathrm{msec}$. Evoked EPSPs had a constant latency of $12 \mathrm{msec}$. At the time indicated by the arrow, a tetanus was delivered to the root consisting of pulses $(8.8 \mathrm{~V}, 0.4$ $\mathrm{msec}$ ) delivered at $100 \mathrm{~Hz}$ in three trains of $1 \mathrm{sec}$ duration separated by 10 $\mathrm{sec}$ intervals. Current injection was stopped for 2 min during the tetanus. $A$, Evoked EPSPs during the baseline (average of 32 sweeps) and after the tetanus (average of 40 sweeps excluding post-tetanic potentiation). $B$, Horizontal lines represent averages of the amplitude of the evoked EPSPs before $(4.4 \pm 0.3 \mathrm{mV}, n=32)$ and after $(8.7 \pm 0.3 \mathrm{mV}, n=40)$ the tetanus. The increase in EPSP amplitude after the tetanus was very significant $(p<0.0001, t$ test $)$. The experiment was repeated three times with similar results.

III-V (of 80-187 NK1R-positive neurons per slice) and $8 \pm 4 \%$ in lamina $\mathrm{X}$ (of 7-53 NK1R-positive neurons per slice). Nevertheless, some internalization could be detected in dendrites of lamina III neurons projecting into lamina I (Fig. 5D, top), although this was less clear than in sections prepared directly from rats injected with capsaicin (Fig. $1 G$ ).

Stimulation with the same number of pulses at lower frequencies (three trains at $10 \mathrm{~Hz}$ for $10 \mathrm{sec}$ or one train at $1 \mathrm{~Hz}$ for $5 \mathrm{~min}$; Fig. 4) failed to increase NK1R internalization in laminae I-II neurons over control levels $(p>0.05)$. Moreover, laminae I-II neurons with internalized NK1Rs were significantly $(p<0.01)$ more numerous in dorsal horns stimulated at $100 \mathrm{~Hz}$ than in dorsal horns stimulated at 1 or $10 \mathrm{~Hz}$, suggesting that the release of SP from afferent terminals is frequency-dependent.

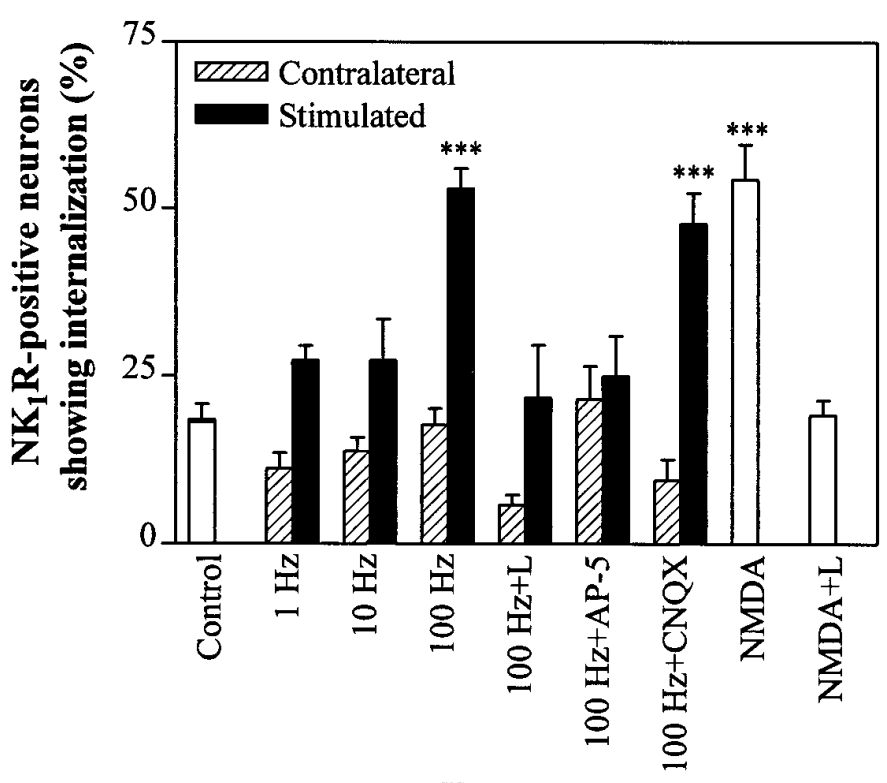

Treatment

Figure 4. Percentage of NK1R-positive neurons in laminae $\mathrm{I}_{-} \mathrm{II}_{\mathrm{o}}$ showing internalization after dorsal root stimulation or incubation with NMDA. One dorsal root was used to stimulate the corresponding side of the slice, whereas the contralateral side served as control. Open bars represent slices that were not electrically stimulated; filled bars represent the stimulated side of the slices; and hatched bars represent the contralateral side. Stimulation was as follows: Control, no stimulation; $1 \mathrm{~Hz}$, one train of $5 \mathrm{~min}$ at $1 \mathrm{~Hz} ; 10 \mathrm{~Hz}$, three trains of $10 \mathrm{sec}$ at $10 \mathrm{~Hz}$ every $10 \mathrm{sec}$; $100 \mathrm{~Hz}$, three trains of $1 \mathrm{sec}$ at $100 \mathrm{~Hz}$ every $10 \mathrm{sec} ; 100 \mathrm{~Hz}+L, 5 \mu \mathrm{M}$ L-703,606 perfused for $10 \mathrm{~min}$ before and after $100 \mathrm{~Hz} ; 100 \mathrm{~Hz}+A P-5,50$ $\mu \mathrm{M}$ AP- 5 perfused for 5 min before and after $100 \mathrm{~Hz} ; 100 \mathrm{~Hz}+C N Q X, 5$ $\mu \mathrm{M}$ CNQX perfused for $10 \mathrm{~min}$ before and after $100 \mathrm{~Hz}$; $N M D A, 100 \mu \mathrm{M}$ NMDA for $1 \mathrm{~min}$ followed by ACSF for $10 \mathrm{~min}$; $N M A+L, 100 \mu \mathrm{M}$ NMDA for $1 \mathrm{~min}$ and $5 \mu \mathrm{M} \mathrm{L}-703,606$ for $10 \mathrm{~min}$ before and after NMDA. Values are mean \pm SEM of four slices (control, $100 \mathrm{~Hz}, 100$ $\mathrm{Hz}+\mathrm{CNQX}, \mathrm{NMDA})$ or three slices (rest). ${ }^{* * *}$ Significantly different from control ( $p<0.001$, ANOVA and Bonferroni's test); these three bars are also significantly different $(p<0.05)$ from any other bars in the figure.

\section{NK1R internalization induced by NMDA receptor activation}

It has been suggested that NMDA autoreceptors control the release of neuropeptides in the dorsal horn (Liu et al., 1994b). To test this hypothesis, the NMDA receptor antagonist AP-5 (50 $\mu \mathrm{M})$ was perfused through the chamber containing the slices for $5 \mathrm{~min}$ before and $5 \mathrm{~min}$ after the $100 \mathrm{~Hz}$ tetanus was delivered to the dorsal root (Fig. $4 ; n=3$ slices). AP-5 significantly decreased $(p<0.001) \mathrm{NK} 1 \mathrm{R}$ internalization in laminae $\mathrm{I}_{-} \mathrm{II}_{\mathrm{o}}$ of the stimulated side of the slices to $22 \pm 5 \%$ (90-122 NK1R-positive neurons per hemislice), a value not significantly different from control $(p>0.05)$, confirming the hypothesis. In contrast, CNQX (5 $\mu \mathrm{M}$; Fig. 4), an antagonist of AMPA and kainate receptors (Honoré et al., 1988), perfused for $10 \mathrm{~min}$ before and $10 \mathrm{~min}$ after the tetanus, did not decrease the internalization produced by the $100 \mathrm{~Hz}$ tetanus in laminae $\mathrm{I}_{-} \mathrm{II}_{\mathrm{o}}$, indicating that non-NMDA glutamate receptors are not involved in the control of SP release.

To investigate the hypothesis further, spinal cord slices were incubated with $100 \mu \mathrm{M}$ NMDA without electrical stimulation (Fig. $4 ; n=4$ slices). Exposure to NMDA was kept short (1 min) to minimize possible cell damage caused by neurotoxicity and was followed by a $10 \mathrm{~min}$ incubation in the absence of drug to leave time for internalization to occur. This treatment resulted in a significant $(p<0.001)$ increase in the number of neurons with 

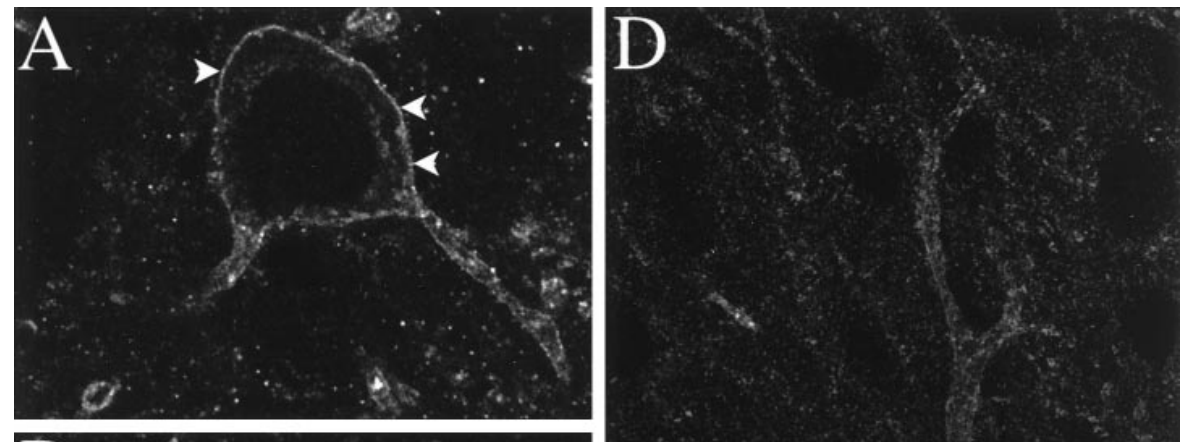

Figure 5. Fluorescent confocal images of NK1Rimmunoreactive neurons in slices electrically stimulated. Stimulation consisted of three trains of 1 $\mathrm{sec}$ at $100 \mathrm{~Hz}$ separated by $10 \mathrm{sec}$, delivered to one of the dorsal roots. Arrowheads indicate surface labeling, and arrows indicate internalized NK1R. $A-C$, Single optical sections. $A$, Lamina I neuron in the contralateral side showing surface immunoreactivity. $B$, Lamina I neuron in the stimulated side showing extensive NK1R internalization. $C$, Lamina III neuron in the contralateral side. $D$, Lamina III neuron in the stimulated side with a dendrite projecting to lamina I (at the top); this is a computer-generated juxtaposition of two confocal images of four (top) or five (bottom) optical sections. Scale bar: $A, B, 10 \mu \mathrm{m} ; C, D, 20 \mu \mathrm{m} . E$, Model of the synergistic action of SP and glutamate at a dorsal horn synapse. 1, Noxious stimuli produce presynaptic depolarization and glutamate release. 2, Presynaptic NMDA receptors are activated by glutamate and depolarization, letting $\mathrm{Ca}^{2+}$ inside the presynaptic button. 3, Increases in presynaptic calcium concentration trigger SP release. 4, SP binds to NK1Rs in surrounding neurons starting the internalization process. 5 , Activated NK1Rs increase postsynaptic responses to glutamate.
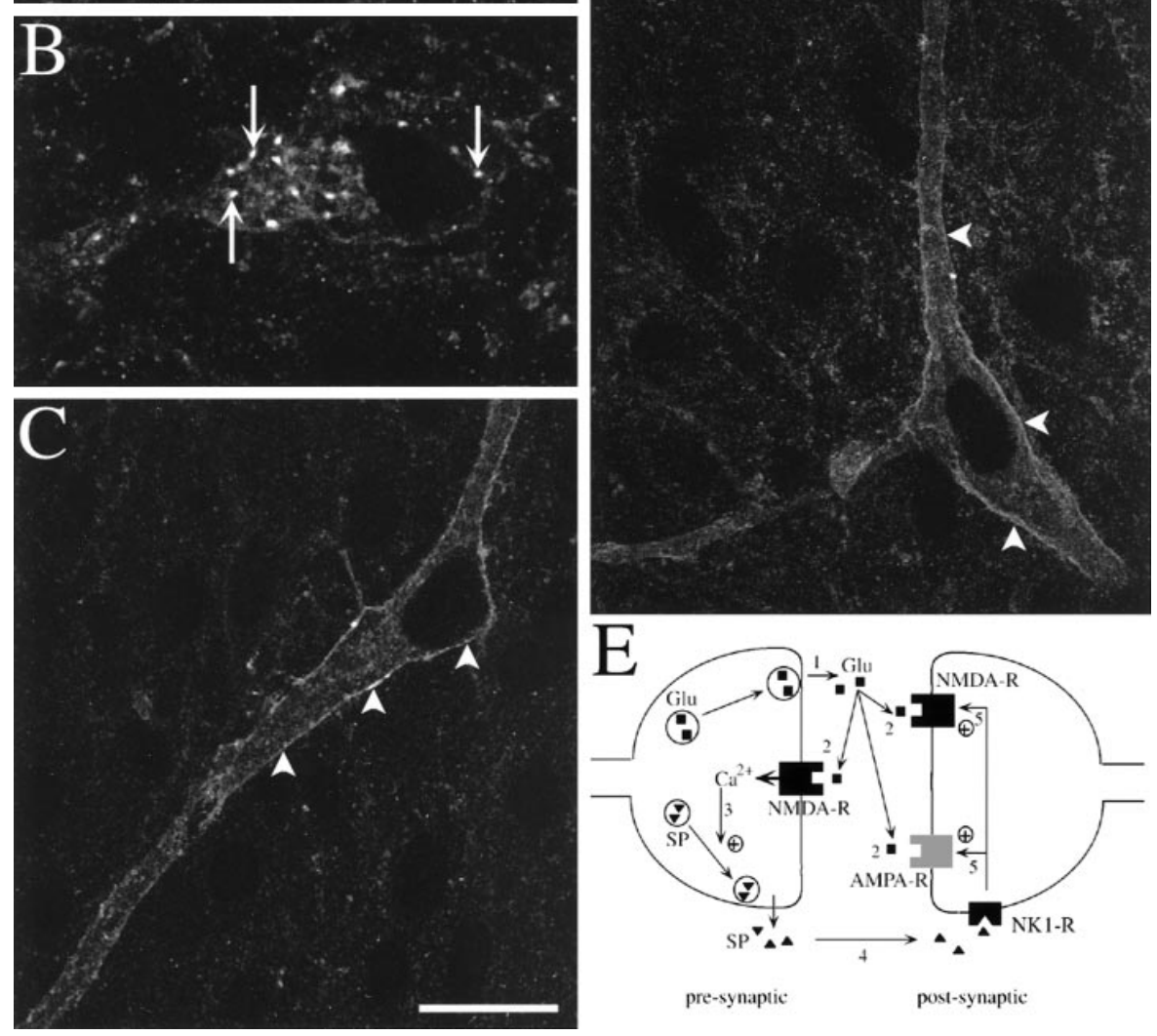

internalized $\mathrm{NK} 1 \mathrm{R}$ in laminae $\mathrm{I}_{-} \mathrm{II}_{\mathrm{o}}$ (to $54 \pm 5 \%$; 144-433 NK1R-positive neurons per slice) but not in laminae III-V (4 \pm $2 \% ; p>0.05 ; 235-371$ NK1R-positive neurons per slice) or lamina $X(5 \pm 3 \% ; p>0.05 ; 19-34$ NK1R-positive neurons per slice). The effect of NMDA was abolished by the NK1R antagonist L-703,606 (5 $\mu \mathrm{M}$; Fig. 4; $p<0.001$ compared with NMDA alone). Hence, NMDA receptors do appear to mediate SP release in the dorsal horn, and this effect seems to be restricted to laminae I and II.

\section{DISCUSSION}

\section{Frequency dependence of SP release}

High-frequency stimulation $(100 \mathrm{~Hz})$ of the dorsal root induced internalization of NK1Rs in laminae $\mathrm{I}_{-} \mathrm{II}_{\mathrm{o}}$ neurons. The internalization was abolished by an SP antagonist, indicating that this stimulation elicited the release of endogenous SP. The same number of pulses delivered at lower frequencies (1 or $10 \mathrm{~Hz}$ ) failed to produce NK1R internalization. It is possible that 1-10 $\mathrm{Hz}$ stimulation elicits some SP release in the dorsal horn but in amounts too low to induce significant NK1R internalization, particularly considering that some SP may leak out of the slices. In any case, our results show that more SP is released at $100 \mathrm{~Hz}$ than at $1-10 \mathrm{~Hz}$. There is evidence that many neuropeptides are released more effectively at higher frequencies of stimulation (Duggan et al., 1995, and references therein). However, there is not a consensus on the role of stimulation frequency in controlling SP release from the spinal cord; although initial reports (Go and Yaksh, 1987) showed that SP release was enhanced by increasing the stimulation frequency from 12 to $20 \mathrm{~Hz}$, Duggan et al. (1995) found that SP release was unchanged over a frequency range of $0.5-20 \mathrm{~Hz}$ but also reported that a greater release of SP was produced by a series of short bursts at high frequency (three pulses at $50-300 \mathrm{~Hz}$ ).

Another issue is the type of fibers stimulated by our protocol. Intracellular recordings showed that the pulses used evoked EPSPs with latencies consistent with the conduction speed of A 2 and C-fibers (Li and Bak, 1976; Swett and Bourassa, 1981). However, because C-fibers do not follow $100 \mathrm{~Hz}$ (McCarthy and Lawson, 1989; Waddell and Lawson, 1990), at least some of the SP that elicits the internalization may be released from A $\partial$-fibers, which follow $100 \mathrm{~Hz}$ and contain SP in $20 \%$ of their terminals (McCarthy and Lawson, 1989; Waddell and Lawson, 1990). Alternatively, our stimulation protocol may have produced short bursts of high frequency in C-fibers before they failed to follow 
the stimulation; these short bursts may be sufficient to elicit substantial SP release from their terminals (Duggan et al., 1995; Ribeiro-da-Silva and Claudio Cuello, 1995). Because SP may diffuse out of the slice, it is possible that release from both A $\partial$ and $\mathrm{C}$-fibers is necessary to produce internalization. Another possibility is that high-frequency stimulation of $\mathrm{A} \partial$ - and $\mathrm{A} \beta$-fibers decrease presynaptic inhibition of $\mathrm{C}$-fibers. When comparing our observations with in vivo results, it has to be kept in mind that slices lack bulbospinal control and input from other spinal segments. Nevertheless, slices with attached roots will be a valuable tool in future studies elucidating what type of afferent activity causes SP release.

\section{Role of NMDA receptors in SP release}

Our findings are consistent with the hypothesis that NMDA autoreceptors control the release of neuropeptides in the dorsal horn (Liu et al., 1994b). NK1R internalization produced by 100 $\mathrm{Hz}$ stimulation of the dorsal root was blocked by the NMDA receptor antagonist AP-5. Moreover, a short incubation with NMDA also elicited NK1R internalization in laminae $\mathrm{I}_{-} \mathrm{II}_{\mathrm{o}}$. The internalization produced by both $100 \mathrm{~Hz}$ stimulation and NMDA application was abolished by an NK1R antagonist, indicating that this internalization was caused by the release of endogenous SP controlled by NMDA receptors. A recent report (Liu et al., 1997) showed a similar increase in NK1R internalization after intrathecal injection of NMDA, which produced pain behavior.

In contrast with the effect of AP-5, CNQX, an antagonist of AMPA and kainate receptors (Honoré et al., 1988), did not decrease the NK1R internalization produced by $100 \mathrm{~Hz}$ stimulation, indicating that non-NMDA glutamate receptors do not mediate the release of SP. Furthermore, CNQX should block synaptic transmission between primary afferents and dorsal horn neurons, because non-NMDA glutamate receptors mediate most of the excitatory synaptic transmission in the dorsal horn (Yoshimura and Jessell, 1990; Randic et al., 1993). Hence, the lack of effect of CNQX suggests that SP is released from primary afferents, which contain half of the neurokinins present in the dorsal horn (Ogawa et al., 1985).

The most plausible explanation for these findings is that the release of SP in the dorsal horn is controlled by presynaptic NMDA receptors in the primary afferents. Alternative explanations are (1) that SP is released by secondary neurons having NMDA receptors postsynaptic to primary afferents; and (2) that postsynaptic NMDA receptors control neurokinin release from the primary afferents by means of a retrograde messenger such as nitric oxide (Schuman and Madison, 1991). The first possibility has to be ruled out, because blocking postsynaptic NMDA receptors does not appreciably decrease synaptic transmission in the dorsal horn (Yoshimura and Jessell, 1990; Randic et al., 1993), whereas all the internalization elicited by dorsal root stimulation appears to be NMDA receptor-dependent (Fig. 4). Moreover, as discussed above, the lack of inhibition of the internalization by CNQX suggests that SP is released from primary afferents.

Although the second explanation cannot be ruled out, there is strong evidence supporting the presence of NMDA autoreceptors in the dorsal horn. NMDA receptors have been detected on the presynaptic terminals of afferent fibers using electron microscopy immunohistochemistry (Liu et al., 1994b). Other reports show that NMDA receptors are expressed in most dorsal root ganglion neurons, including the small cells related to $\mathrm{C}$ - and $\mathrm{A} \partial$-fibers (Sato et al., 1993). Furthermore, glutamate coexists with SP in primary afferent terminals in the dorsal horn (Battaglia and
Rustioni, 1988; De Biasi and Rustoni, 1988). Nevertheless, experiments ruling out the involvement of retrograde messengers in SP release elicited by NMDA application are necessary to confirm that these NMDA receptors are indeed presynaptic.

\section{Sites of release of SP}

NMDA and high-frequency stimulation produced internalization exclusively in neurons in laminae $\mathrm{I}-\mathrm{II}_{\mathrm{o}}$, although internalization seems to occur also in the dendrites of laminae III-V neurons that extend into lamina I. This is probably attributable to the fact that SP is released in laminae I and II in amounts too small to reach laminae III-V (Liu et al., 1994a; Duggan et al., 1995; Ribeiroda-Silva and Claudio Cuello, 1995). Alternative explanations are that internalization mechanisms are less active in laminae III-V, as suggested by the limited internalization produced by SP in this region, or that laminae III-V have a higher content of NEP.

Studying SP release in spinal cord slices has two potential problems: (1) released SP may diffuse out of the slices before it can reach deeper laminae; and (2) dorsal root fibers running rostrally before entering the dorsal horn are severed in the slices. Nevertheless, these problems do not invalidate our conclusion that SP release occurs mainly in laminae I and II, because NK1R internalization elicited by NMDA application to the slices or by noxious stimulation in vivo (Fig. 1G) (Mantyh et al., 1995) was also restricted to laminae I and II.

\section{NK1Rs and dorsal horn LTP}

LTP of synapses between afferent fibers, including C-fibers, and neurons in the superficial dorsal horn has been described by other investigators (Randic et al., 1993; Liu and Sandkühler, 1995). We have replicated these results here to show that the same $100 \mathrm{~Hz}$ tetanus that we used to produce NK1R internalization is able to induce LTP, confirming the integrity of the synapses. Both dorsal horn LTP and NK1R internalization are induced by highfrequency stimulation and require the activation of NMDA receptors. In vivo field potential recordings (Sandkühler et al., 1995) have shown that NK1R antagonists block the induction of dorsal horn LTP, raising the possibility that NK1Rs participate in dorsal horn LTP. The main problem with this idea is that LTP can be induced in half of the neurons in laminae I and II (Randic et al., 1993), whereas NK1R-positive neurons are scarce in lamina II (Liu et al., 1994a) and represent only $5-10 \%$ of the neurons in lamina I (Brown et al., 1995). Hence, LTP can be induced in neurons lacking NK1Rs. Further studies are necessary to elucidate whether the similarities between the production of LTP and SP release in the dorsal horn are purely coincidental, or whether neurons with NK1Rs somehow participate in the induction of LTP in other neurons.

\section{Conclusion}

Our results are consistent with the following model for the synergistic action of neurokinins and glutamate in the dorsal horn (Fig. 5E). (1) Noxious stimuli induce high-frequency action potentials in $\mathrm{A} \partial$ - and $\mathrm{C}$-fibers, producing presynaptic depolarization and glutamate release from these terminals. (2) Presynaptic depolarization and extracellular glutamate activate NMDA autoreceptors, which let calcium inside the presynaptic button. (3) This produces a further increase in the intracellular calcium concentration of the synaptic button, triggering SP release from dense core vesicles. (4) SP binds to NK1Rs in surrounding neurons, starting the internalization process. (5) Activated NK1Rs increase postsynaptic responses to glutamate (Randic et al., 1990; 
Rusin et al., 1993a,b) through signal transduction pathways, leading to an increase in neuronal excitability.

\section{REFERENCES}

Battaglia G, Rustioni A (1988) Coexistence of glutamate and substance $\mathrm{P}$ in dorsal root ganglion neurons of the rat and monkey. J Comp Neurol 277:297-312.

Bleazard L, Hill RG, Morris R (1994) The correlation between the distribution of the NK1 receptor and the actions of tachykinins agonists in the dorsal horn of the rat indicates that substance $\mathrm{P}$ does not have a functional role on substantia gelatinosa (lamina II) neurons. J Neurosci 14:7655-7664.

Brown JL, Liu H, Maggio JE, Vigna SR, Mantyh PW, Basbaum AI (1995) Morphological characterization of substance $P$ receptorimmunoreactive neurons in the rat spinal cord and trigeminal nucleus caudalis. J Comp Neurol 356:327-344.

Cascieri MA, Ber E, Fong TM, Sadoski S, Bansal A, Swain C, Seward E, Frances B, Burns D, Strader CD (1992) Characterization of the binding of a potent, selective, radioiodinated antagonist to the human neurokinin-1 receptor. Mol Pharmacol 42:458-463.

Davies SN, Lodge D (1987) Evidence for involvement of $\mathrm{N}$ methylaspartate receptors in "wind-up" of class 2 neurones in the dorsal horn of the rat. Brain Res 424:402-406.

De Biasi S, Rustoni A (1988) Glutamate and substance P coexist in primary afferent terminals in the superficial laminae of spinal cord. Proc Natl Acad Sci USA 85:7820-7824.

Dickenson AH, Sullivan AF (1987) Evidence for a role of the NMDA receptor in the frequency dependent potentiation of deep rat dorsa horn nociceptive neurones following $\mathrm{C}$ fibre stimulation. Neuropharmacology 26:1235-1238.

Dougherty PM, Palecek J, Paleckova V, Willis W (1995) Infusion of substance $\mathrm{P}$ or neurokinin A by microdialysis alters responses of primate spinothalamic tract neurons to cutaneous stimuli and to iontophoretically released excitatory amino acids. Pain 61:411-425.

Duggan AW, Schaible H-G, Hope PJ, Lang CW (1992) Effect of peptidase inhibition on the pattern of intraspinally released immunoreactive substance $\mathrm{P}$ detected with antibody microprobes. Brain Res 579:261-269.

Duggan AW, Riley RC, Mark MA, MacMillan SJA, Schaible H-G (1995) Afferent volley patterns and the spinal release of immunoreactive substance $\mathrm{P}$ in the dorsal horn of the anesthetized spinal cat. Neuroscience 65:849-858.

Garland AM, Grady EF, Lovett M, Vigna SR, Frucht MM, Krause JE, Bunnett NW (1996) Mechanisms of desensitization and resensitization of $\mathrm{G}$ protein-coupled neurokinin ${ }_{1}$ and neurokinin ${ }_{2}$ receptors. Mol Pharmacol 49:438-446.

Go VLW, Yaksh TL (1987) Release of substance P from the cat spinal cord. J Physiol (Lond) 391:141-167.

Grady EF, Gamp PD, Jones E, Baluk P, McDonald DM, Payan DG, Bunnett NW (1996) Endocytosis and recycling of neurokinin receptors in enteric neurons. Neuroscience 75:1239-1254.

Honoré T, Davies SN, Drejer J, Fletcher EJ, Jacobsen P, Lodge D, Nielsen FE (1988) Quinoxalinediones: potent competitive nonNMDA glutamate receptor antagonists. Science 241:701-703.

Kellstein DE, Price DD, Hayes RL, Mayer DJ (1990) Evidence that substance P selectively modulates C-fiber-evoked discharges of dorsal horn nociceptive neurons. Brain Res 526:291-298.

Li CL, Bak A (1976) Excitability characteristics of the A- and C-fibers in a peripheral nerve. Exp Neurol 50:67-79.

Liu H, Brown JL, Jasmin L, Maggio JE, Vigna SR, Mantyh PW, Basbaum AI (1994a) Synaptic relationship between substance P and the substance $\mathrm{P}$ receptor: light and electron microscopic characterization of the mismatch between neuropeptides and their receptors. Proc Natl Acad Sci USA 91:1009-1013.

Liu H, Wang H, Sheng M, Jan LY, Jan YN, Basbaum AI (1994b) Evidence for presynaptic $N$-methyl-D-aspartate autoreceptors in the spinal cord dorsal horn. Proc Natl Acad Sci USA 91:8383-8387.

Liu H, Mantyh PW, Basbaum AI (1997) NMDA-receptor regulation of substance $\mathrm{P}$ release from primary afferent nociceptors. Nature 386:721-724.

Liu X-G, Sandkühler J (1995) Long-term potentiation of C-fiber-evoked potentials in the rat spinal dorsal horn is prevented by spinal $N$-methylD-aspartic acid receptor blockage. Neurosci Lett 191:43-46.

Mantyh PW, DeMaster E, Malhotra A, Ghilardi JR, Rogers SD, Mantyh CR, Liu H, Basbaum AI, Vigna SR, Maggio JE, Simone DA (1995) Receptor endocytosis and dendritic reshaping in spinal neurons after somatosensory stimulation. Science 268:1629-1632.

McCarthy PW, Lawson SN (1989) Cell type and conduction velocity of rat primary sensory neurons with substance P-like immunoreactivity. Neuroscience 28:745-753.

McMahon SB, Lewin GR, Wall PD (1993) Central hyperexcitability triggered by noxious inputs. Curr Opin Neurobiol 3:602-610.

Mendell LM (1966) Physiological properties of unmyelinated fiber projection to the spinal cord. Exp Neurol 16:316-332.

Murase K, Randic M (1984) Actions of substance P on rat spinal dorsal horn neurones. J Physiol (Lond) 346:203-217.

Ogawa T, Kanazawa I, Kimura S (1985) Regional distribution of substance $\mathrm{P}$, neurokinin A and neurokinin B in rat spinal cord, nerve roots and dorsal root ganglia, and the effects of dorsal root section or spinal transection. Brain Res 359:152-157.

Randic M, Hecimovic H, Ryu PD (1990) Substance P modulates glutamate-induced currents in acutely isolated rat spinal dorsal horn neurones. Neurosci Lett 117:74-80.

Randic M, Jiang MC, Cerne R (1993) Long-term potentiation and longterm depression of primary afferent neurotransmission in the rat spinal cord. J Neurosci 13:5228-5241.

Ribeiro-da-Silva A, Claudio Cuello A (1995) Organization of peptidergic neurons in the dorsal horn of the spinal cord: anatomical and functional correlates. Prog Brain Res 104:41-59.

Routh VH, Helke CJ (1995) Tachykinin receptors in the spinal cord. Prog Brain Res 104:93-108.

Rusin KI, Bleakman D, Chard PS, Randic M, Miller RJ (1993a) Tachykinins potentiate $N$-methyl-D-aspartate responses in acutely isolated neurons from the dorsal horn. J Neurochem 60:952-960.

Rusin KI, Jiang MC, Cerne R, Randic M (1993b) Interactions between excitatory amino acids and tachykinins in the rat spinal dorsal horn. Brain Res Bull 30:329-338.

Sandkühler J, Liu X-G, Zimmermann M (1995) N-Methyl-D-aspartate and neurokinin receptors are critical for the induction of long-term potentiation of C-fiber-evoked field potentials in rat spinal dorsal horn. Soc Neurosci Abstr 21:645.6.

Sato K, Kiyama H, Tae Park H, Tohyama M (1993) AMPA, KA and NMDA receptors are expressed in the rat DRG neurones. NeuroReport 4:1263-1265.

Schuman EM, Madison DV (1991) A requirement for the intercellular messenger nitric oxide in long-term potentiation. Science 254:1503-1506.

Swett JE, Bourassa CM (1981) Electrical stimulation of peripheral nerve. In: Electrical stimulation research techniques (Patterson MM, Kesner RP, eds), pp 243-295. New York: Academic.

Vigna SR, Bowden JJ, McDonald DM, Fisher J, Okamoto A, McVey DC, Payan DG, Bunnett NW (1994) Characterization of antibodies to the rat substance $\mathrm{P}(\mathrm{NK}-1)$ receptor and to a chimeric substance $\mathrm{P}$ receptor expressed in mammalian cells. J Neurosci 14:834-845.

Waddell PJ, Lawson SN (1990) Electrophysiological properties of subpopulations of rat dorsal root ganglion neurons in vitro. Neuroscience 36:811-822.

Womack MD, MacDermott AB, Jessell TM (1988) Sensory transmitters regulate intracellular calcium in dorsal horn neurons. Nature 334:351-353.

Xu X-J, Dalsgaard C-J, Wiesenfeld-Hallin Z (1992) Spinal substance P and $N$-methyl-D-aspartate receptors are coactivated in the induction of central sensitization of the nociceptive flexor reflex. Neuroscience 51:641-648.

Yaksh TL (1993) The spinal pharmacology of facilitation of afferent processing evoked by high-threshold afferent input of the postinjury pain state. Curr Opin Neurol Neurosurg 6:250-256.

Yoshimura M, Jessell T (1990) Amino acid-mediated EPSPs at primary afferent synapses with substantia gelatinosa neurones in the rat spinal cord. J Physiol (Lond) 430:315-335.

Zieglgänsberger W, Tolle TR (1993) The pharmacology of pain signaling. Curr Opin Neurobiol 3:611-618. 